\title{
Patient participation in the development of a customized m-Health intervention to improve medication adherence in poorly adherent individuals with bipolar disorder (BD) and hypertension (HTN)
}

\author{
Carol Blixen*1, Martha Sajatovic ${ }^{1,2}$, David J. Moore ${ }^{3}$, Colin Depp $^{3}$, Clint Cushman ${ }^{3}$, Jamie Cage ${ }^{4}$, Marina Barboza ${ }^{2}$, \\ Logan Eskew ${ }^{2}$, Peter Klein ${ }^{1}$, Jennifer B. Levin ${ }^{1,2}$ \\ ${ }^{1}$ Department of Psychiatry, Case Western Reserve University School of Medicine, Neurological and Behavioral Outcomes Center, \\ Cleveland, Ohio, USA \\ ${ }^{2}$ Department of Psychiatry, University Hospitals Cleveland Medical Center, Cleveland State University, Cleveland, Ohio, USA \\ ${ }^{3}$ Department of Psychiatry, University of California, San Diego, La Jolla, California, USA \\ ${ }^{4}$ School of Social Work, Virginia Commonwealth University, Virginia, USA
}

Received: November 30, 2017

Accepted: February 22, 2018

Online Published: March 5, 2018

DOI: $10.5430 /$ ijh.v4n1p25

URL: https://doi.org/10.5430/ijh.v4n1p25

\begin{abstract}
Objective: Individuals living with bipolar disorder (BD) have poorer management of chronic medical conditions such as hypertension (HTN), and worse treatment adherence than the general population. The study objective was to obtain information from patients with both BD and HTN that would inform the development of an m-Health intervention to improve medication adherence for poorly adherent individuals living with both these chronic illnesses.

Methods: Focus group methodology was used to collect information from 13 participants on perceived barriers and facilitators to BD and HTN medication adherence, as well as feedback on the demonstration and use of a bidirectional text messaging system for medication reminders. Focus groups were audiotaped, transcribed verbatim, and analyzed using content analysis with an emphasis on dominant themes.

Results: Forgetfulness was the most frequently mentioned barrier to taking antihypertensive medications, and decisions about taking them were often influenced by BD mood fluctuations and the burden of having to take "too many pills" for both chronic illnesses. Participants' feedback about the use of a text-messaging system to help with medication adherence for BD and HTN was very positive, and their suggestions for modification were incorporated into a more customized system for testing in a Phase 2 trial.

Conclusions: Our findings indicate that patient engagement in the development of an $\mathrm{m}$-Health intervention has the potential to improve adherence with both BD and HTN medications in individuals with known sub-optimal adherence. Patient engagement in health care is essential if we are to optimize patient outcomes.
\end{abstract}

Key Words: Medication adherence, Bipolar disorder, Hypertension, m-Health technology

\footnotetext{
*Correspondence: Carol Blixen; Email: cxb28@ case.edu; Address: Department of Psychiatry, Case Western Reserve University School of Medicine, Neurological and Behavioral Outcomes Center, Cleveland, Ohio, USA.
} 


\section{INTRODUCTION}

Research has shown that individuals who suffer from serious mental illness, including Bipolar Disorder (BD), also experience much higher rates of chronic medical conditions such as hypertension (HTN), cardiovascular disease (CVD), and diabetes ${ }^{[1]}$ than the general population. Furthermore, individuals with $\mathrm{BD}$ often have poorer management of their chronic medical conditions, and worse treatment adherence compared to the general population. This leads to increased hospital visits and a premature mortality rate of approximately twice that of the general population ${ }^{[2,3]}$ with a life expectancy that is shortened by $10-30$ years. ${ }^{[4]}$

CVD has been reported to be the leading cause of death in $\mathrm{BD}^{[5,6,8]}$ and between $25 \%$ and $45 \%$ of those living with $\mathrm{BD}$ suffer from HTN. ${ }^{[9]}$ While effective management of hypertension is known to reduce cardiovascular events like stroke or heart attack, poor adherence to antihypertensives has been estimated to occur in $50 \%-80 \%$ of patients with BD. ${ }^{[10,11]}$ Literature reviews of adherence interventions indicate that no single intervention has strong evidence for improving antihypertensive adherence. ${ }^{[12,13]}$ Among the few interventions to improve adherence in $\mathrm{BD}$ that do exist, the focus is on psychotropic medications rather than treatments for comorbid medical conditions. ${ }^{[13,14]}$ Therefore, novel approaches to improving CVD medication adherence are needed for BD.

Several studies have shown that m-Health tools can be useful to support behavior change. ${ }^{[15]}$ Text messaging has been shown to improve treatment adherence, symptom surveillance, and appointment attendance in various psychiatric populations including among individuals with substance abuse, schizophrenia, affective disorders, or those at risk for suicide. ${ }^{[16]}$ There is also increasing evidence for the usability, feasibility, and effectiveness of $\mathrm{m}$-Health tools in serious mental illness (SMI) generally, and in BD specifically. ${ }^{[17,18]}$ Automated text-messaging has been used to improve adherence to HIV and BD medications among persons with these co-occurring conditions, and evidence indicates that improved antiretroviral dose timing is associated with text reminders and motivational feedback. ${ }^{[19]}$ Furthermore, text reports of adherence were significantly associated with adherence measures, including objective electronic monitoring through MEMS caps placed on medication bottles. ${ }^{[19]}$ In a study with HIV-infected methamphetamine users, response rates to text messages ranged from $69 \%-72.9 \%$, ${ }^{[20]}$ an indication of high engagement. In sum, text-messaging interventions have the advantage of real-time adherence data collection $^{[21]}$ which can then inform interventions and allow for the personalization of message type to target an individual's barriers to adherence as well as optimize frequency of messages.
A bidirectional text-messaging system called Individualized Texting for Adherence Building (iTAB) has been used in complex populations where medication adherence rates are both suboptimal and critical for health outcomes. ${ }^{[19,20,22]}$ However, the iTAB platform has not been developed or tested as a medication adherence intervention for addressing both psychotropic and non-psychiatric non-adherence in a psychiatric population at high CV risk. To address this gap, the study team at Case Western Reserve University School of Medicine, who are pioneers in understanding and improving medication adherence in BD, collaborated with the study team at the University of California San Diego, who developed the iTAB platform, to develop and customize the iTAB platform for improving medication adherence in patients with both BD and HTN. Given the importance of user-centered design in engaging individuals in behavior change, we involved patients with both these chronic conditions in Phase I, the developmental phase of this study.

\section{Methods}

\subsection{Overview of Phase I}

We used qualitative methods to obtain information that will inform a subsequent Phase 2 customized m-Health texting intervention built on the iTAB platform, called iTAB-CV. Qualitative inquiry is an appropriate framework for learning how patients conceptualize their experience of disease, and qualitative research techniques have become an integral component to developing health promotion interventions in special populations. ${ }^{[23]}$ Data were collected using a focus group format because of the strength in generating new ideas through group interaction, and for facilitating access to the diverse opinions of a number of individuals in a short space of time. ${ }^{[24]}$ The issues discussed in the focus groups included perceived adherence issues, information about comfort with technology-based tools to help with medication adherence, and feedback and suggestions for modification and customization of the iTAB platform for the present $\mathrm{m}$ Health intervention.

\subsection{Sample and setting}

A purposive sample of 30 possible participants (20 females and 10 males), who were receiving treatment in the Department of Psychiatry at an urban academic medical center, was contacted by phone for participation in the focus groups. Inclusion criteria consisted of being 21 years or older, ability to participate in a focus group, documented clinical diagnoses of BD and HTN, and having current or past self-reported difficulties with antihypertensive medication adherence. Of the 30 potential focus group participants, seven individuals could not be reached because of wrong phone numbers, and four others were either not interested, did not call back, or did not 
fit the inclusion criteria. The 19 remaining individuals were then scheduled to attend the focus groups but, despite frequent telephone reminders, six ( 3 males \& 3 females) did not attend, leaving a sample size of 13 focus group participants.

The study was approved by the Institutional Review Board (IRB) of University Hospitals Cleveland Medical Center in Cleveland, Ohio, United States. Additionally, all 13 focus group participants signed an informed consent form. Three 90-minute focus groups, with 3-5 participants in each group, were then conducted until little new information was generated, or theoretical saturation had occurred. ${ }^{[24]}$ The focus groups were held in the afternoon in a small conference room in the Department of Psychiatry at the academic medical center and a light snack was served.

Table 1 illustrates the demographic and clinical characteristics of the 13 focus group participants. The mean age of the focus group participants $(\mathrm{N}=13)$ was 52.8 years (SD =9.46) with a range of 35-69 years, and the majority were African-American (92.3\%) females (79.6\%). Twelve of the participants (92\%) were unmarried, and $10(76.92 \%)$ were unemployed at the time the focus groups occurred. The mean level of education was 11.92 years $(\mathrm{SD}=1.66)$. Age of onset of $\mathrm{BD}$ was 28.77 years $(\mathrm{SD}=12.90)$, and the average number of hypertensive medications taken was 1.77 (SD = $0.58)$ with a range of 1-3. The demographics of the sample are consistent with those of the recruitment area, a midsized Midwestern city, with a majority of African-American (92\%), female (54\%), English speakers (97\%), with a median age of (42.8 years), and $42.6 \%$ living below the poverty line. ${ }^{[25]}$

\subsection{Qualitative data collection and analysis}

A semi-structured focus group interview guide was developed by a multidisciplinary team from Case Western Reserve University School of Medicine (a health-services qualitative researcher, a psychiatrist, a clinical psychologist) and from the University of San Diego's health systems group under the direction of a clinical psychologist and m-Health specialist. The guide explored participants' views on barriers and facilitators to medication adherence, their attitudes and decision making toward taking medications, information related to m-Health technology, and feedback on the iTAB platform. For example, under the topic "barriers to taking HTN medication", the following question was asked: "We know that various things get in the way of people taking their HTN medication as prescribed. What things get you off track, or get in the way of taking your high blood pressure medication?" Under the topic "decision making about taking medications", the participants were asked: "In what ways is your decision making about taking medications for high blood pressure similar/dissimilar to your decision making

Published by Sciedu Press about taking medications for bipolar disorder?" The guide also included examples of follow-up probes such as "would you explain further," "please describe what you mean," and "would you give me an example." These data collection methods allowed interviewees to express their opinions and ideas in their own words and they are an appropriate strategy for learning the vocabulary and discovering the thinking pattern of the target audience, as well as for discovering unanticipated findings and exploring hidden meaning. ${ }^{[26]}$

Table 1. Demographic and clinical characteristics of the focus group sample $(\mathrm{N}=13)$

\begin{tabular}{ll}
\hline Variable & N (\%) or mean (SD) \\
\hline Age (years) & $52.8(9.46)$ \\
Gender & $10(79.60 \%)$ \\
$\quad$ Female & $3(20.40 \%)$ \\
$\quad$ Male & $11.92(1.66)$ \\
Education years & \\
Race & $1(7.70 \%)$ \\
Caucasian & $12(92.30 \%)$ \\
African-American & \\
Marital status & $4(0.31 \%)$ \\
Single, never married & $1(0.08 \%)$ \\
Married & $6(0.46 \%)$ \\
Separated/Divorced/Don't know & $2(0.15 \%)$ \\
Widowed & \\
Working status & $1(0.08 \%)$ \\
Full-time & $1(0.08 \%)$ \\
Part-time & $1(0.08 \%)$ \\
Unemployed but expected to work & $9(0.69 \%)$ \\
Unemployed but disabled & $1(0.08 \%)$ \\
Other & $28.77(12.90)$ \\
Age of onset of bipolar disorder & $1.77(0.58)$ \\
Number of antihypertensives prescribed &
\end{tabular}

A facilitator recorded observations on a flip chart and reviewed statements with the participants at regular intervals during the discussion. A debriefing session between the moderator (JL) and facilitator (CB) after each session provided an opportunity for sharing first impressions, summarizing key findings, and comparing each session with previous ones so that, if necessary, modifications in the focus group guide could be made. All three focus groups and debriefing sessions were audio-recorded and transcribed verbatim. Participants were compensated $\$ 25$ for their time and effort, as well as reimbursement for transportation.

In qualitative research, data collection, coding and analysis occur simultaneously rather than sequentially. ${ }^{[27]}$ Emerging insights can be incorporated into later stages of data genera- 
tion, enhancing the comprehensiveness of the results. ${ }^{[27,28]}$ Transcript-based analysis ${ }^{[26,29,30]}$ was used to analyze all data. In this method, the researcher uses the transcription itself as the source of the textural data to be analyzed. We used a thematic content analysis approach to data analysis, encompassing open, axial and sequential coding, and the constant comparative method to generate constructs (themes) and elaborate the relationship among constructs. ${ }^{[26,29]}$

A coding dictionary that included mutually-exclusive code definitions was then constructed. The coding structure was reviewed after a preliminary analysis of a sub-sample of transcripts, and the dictionary was refined through comparison, categorization and discussion of each code's properties and dimensions. ${ }^{[28,29]}$ Two of the investigators $(\mathrm{CB}, \mathrm{JL})$ independently coded each transcript to ensure consistency and transparency of the coding; discrepancies were resolved by discussion. ${ }^{[30]}$ Triangulation of data was achieved by comparing observations of written data that emerged during the focus groups: 1) notes made on a flip chart by the facilitator;
2) notes made by staff observers (JC, PK); and 3) having another member of the research team (JC) listen to the tapes and compare the content to the verbatim transcripts. ${ }^{[31]}$ To further enhance validity of the data, an audit trail (researchers' analysis, notes, minutes of researchers' meetings) was performed throughout the research process. ${ }^{[32]}$

\section{RESULTS}

Transcript-based analysis generated textual data on the following four patient centered issues that will inform the development and modification of the m-Health intervention: (1) Barriers to Antihypertensive Medication Adherence, (2) Facilitators to Antihypertensive Medication Adherence, (3) Use and Comfort with Technologies/Texting, and (4) Demonstration and Feedback of iTAB.

\subsection{Barriers to antihypertensive medication adherence}

In Table 2, themes and illustrative quotations emerging from the discussion of perceived barriers to anti-hypertensive medication adherence among participants with BD are presented.

Table 2. Barriers to antihypertensive medication adherence among participants with bipolar disorder (BD) (n=13)

\begin{tabular}{|c|c|}
\hline Themes and Categories & Illustrative Quotations from Respondents \\
\hline \multirow{2}{*}{$\begin{array}{l}\text { Forgetfulness and } \\
\text { Competing Demands }\end{array}$} & $\begin{array}{l}\text { "The only thing that prevents me from taking mine is I forget it. I just plain forget it. Maybe rushing out } \\
\text { in the morning or something." Respondent \#6 }\end{array}$ \\
\hline & $\begin{array}{l}\text { "Just the hustle-and-bustle of everyday! Sometimes you wake up and you have an appointment and } \\
\text { you're rushing and stuff like that." Respondent \#8 }\end{array}$ \\
\hline \multirow[t]{2}{*}{ Side Effects } & $\begin{array}{l}\text { "I have a problem taking that 'cause I'm like at the bathroom all night long. Every } 30 \text { minutes it seems } \\
\text { like I got to go to the bathroom and that's from taking that water pill, so sometimes I'll skip it." } \\
\text { Respondent \#10 }\end{array}$ \\
\hline & “They cause dizziness so I try to not take both of them at the same time.” Respondent \#2 \\
\hline \multirow[t]{2}{*}{ Attitudes } & $\begin{array}{l}\text { Sometimes I look at that blood pressure pill and the rest of them like damn I don't feel like taking it, I'll } \\
\text { do it tomorrow." Respondent \#11 }\end{array}$ \\
\hline & "Whether I take the blood pressure meds or don't take them, I'll still wake up dead.” Respondent \#13 \\
\hline \multirow[t]{2}{*}{ Decision Making } & $\begin{array}{l}\text { "I think this pill looks like the one for this and that pill looks like the one for that and all } 12 \text { pills are } \\
\text { different colors! I'm like I ain't gonna take all these pills, and then I split them in half and just take half } \\
\text { of them randomly." Respondent \#11 }\end{array}$ \\
\hline & $\begin{array}{l}\text { "When I'm up, (mood), I feel like “'I don't need that. If I'm like feeling too good to worry about what } \\
\text { my BP is because I'm moving around, running to work, or helping a friend.'” Respondent \#5 }\end{array}$ \\
\hline
\end{tabular}

\subsubsection{Forgetfulness and competing demands}

As noted in Table 2, forgetfulness, which was often associated with the competing demands of life, was perceived to be the number one barrier to taking anti-hypertensive medications:

"I'm very, very forgetful so I forgot to take my pills. It's too late then. So it will be like almost the next day that I remember and you're not supposed to take them like that. It's just that I get up and then I start doing things like going to the bathroom or whatever, and then I start doing something else, and it just slips my mind." Respondent \#1

"You know I work two jobs, I go to school fulltime and so it's busy and then I volunteer at another place so my plate is pretty full and sometimes I forget to take the pill." Respondent \#10 
For some respondents, forgetting to take medications for BD often led to forgetting to take medications for HTN:

"If I forget to take the bipolar meds then I forget to take the one for my blood pressure. If I don't take one then I'm not going to take the other one.” Respondent \#7

\subsubsection{Perceived side effects of antihypertensive medica- tions}

Side effects of medications can often present a barrier to medication adherence for many persons living with a chronic disease. Beside occasional dizziness, frequent urination was the most often cited side effect of antihypertensive medication use among our participants:

"So it makes you keep using the bathroom! And so I will take it in the evening but sometimes I forget because I usually take them in the morning. I switched the time because if I am at work or if I have to be somewhere, I have to use the bathroom ten times if I drink water." Respondent \#10

Another issue was difficulty determining the source of the side effect. Because participants in our study were taking medications for both BD and HTN, they were unsure which medication caused the side effect they experienced. As such, participants reported sometimes discontinuing one medication in order to determine the medication responsible for the side effects:

"The side effect was personal and I didn't know what pill might be doing it, and so I'd stop one medication at a time to see which one it was." Respondent \#3

\subsubsection{Decision making}

In addition to having some negative attitudes about taking HTN medications, decisions about taking them were often influenced by having to take "too many pills", as well as the symptoms associated with BD:

"When I'm feeling in that 'up' state of mind, I don't take it." Respondent \#2

"I'm talking about when I didn't take it because I was depressed or stuck up in my own little realm. I've done it more than 10 times before." Respondent \#4

\subsubsection{Takes one but not the other}

Having to take pills for multiple chronic conditions can be overwhelming for patients. During the focus groups, the moderator explored ways that participants' decisions about taking medications for HTN were similar to, or different

Published by Sciedu Press from, decisions about taking medications for BD. For some participants, decisions to not take their BD medications were because they felt they "didn't need them", while others made decisions on whether one medication was more important than the other:

"It was easier to skip the psych meds. I don't need this one, I don't need that one, until you become a monster the next day”. Respondent \#3

"I mean I've played with everything but what I really don't play with now is my bipolar medicine. I try to make sure that I take that because my track record shows that when I don't, things begin to happen. So where I was in doubt when I first got on them, I am thoroughly convinced that I need them and I take my bipolar medicine more than I take my blood pressure medicine." Respondent \#8

\subsubsection{Random choices}

For some, choices to take or not take medications for BD and HTN were random decisions:

“Sometimes I'm going to take my psych meds today, and sometimes I don't want no psych meds today, but I feel it's really important for me to take my blood pressure medicine. Or I take my psych meds and don't take my high blood pressure medicine. So it's not all or none, sometimes you take one and not the other. It could go either way.” Respondent \#7

Others made their decisions about taking medications around their alcohol intake:

"When I'm drinking I usually don't take them because the alcohol just kills your medicine anyway. So, usually I don't mix them with the alcohol. If I'm going to drink, I drink, but I won't mess with any of the medicines." Respondent \#5

"The effects of the Seroquel are intensified when you drink alcohol, and I have a beer here and there. So that's usually the reason why I don't take it because I don't want any adverse side effects. So it's kind of like thinking one step ahead." Respondent \#2

\subsection{Facilitators to anti-hypertensive medication adher- ence}

In Table 3, themes and illustrative quotations emerging from the discussion of facilitators to antihypertensive medication adherence among participants with BD are presented. 
Table 3. Facilitators to antihypertensive medication adherence among participants with bipolar disorder (BD) ( $\mathrm{n}=13$ )

\begin{tabular}{ll}
\hline Themes and Categories & Illustrative Quotations from Respondents \\
\hline & "Like my friend that calls me. She might call me maybe 3 times a day, and each time she calls she asks \\
me do I take my medicine, do I take it, did I take it!” Respondent \#13 & "My sister will call me about 8 or 9 o'clock, when she takes her medicine, and reminds me to take my \\
Supportive Others & "I take mine soon as I open my eyes, otherwise I forget. And what’s helped me is having that pill box, \\
& you know. That tells you morning, afternoon, and evening medicines." Respondent \#5 \\
& "So I put a calendar on my door, and I got one on my refrigerator, so I can remind myself and it’s \\
Crossed out that I took my medicine." Respondent \#10 & "I might have a stroke, heart attack, burst an artery, or pass out." Respondent \#3
\end{tabular}

\subsubsection{Supportive others}

As illustrated in Table 3, support from family and friends, in the form of telephone calls to encourage and remind participants to take their medications, was cited as a major facilitator to medication adherence:

"My mom would call all the time and ask 'are you taking your meds?' She took seriousness to this group, which I was attending and got involved and read everything. So she always calls and reminds me to take my meds." Respondent \#3

Although reminder calls about medication adherence were appreciated, sometimes the repeated calls could be perceived as annoying, but fulfilled their purpose:

"She calls me wherever I go and reminds me to take my meds. 'You need to take your meds, you need to stay at home and take those meds, you don't need to be over there, you need to be home taking your meds. She says it so much I just take the pill, you know, because I somewhat need that pill. She does irritate me sometimes, but she means well."” Respondent \#11

\subsubsection{Using reminders}

In addition to telephone reminders from family and friends, other reminders, initiated by the participants, themselves, included displaying a reminder calendar in a frequently accessed place, establishing a routine for taking medications, using pill boxes, and placing medications in visible places:

"I use a pill box where you can separate your pills in a way where they don't affect you with side effects or pass out on somebody for taking too much. I found the perfect balance!" Respondent \#3

"Well me, umm I don't have a pill box thing but I will take a pill out and I will just lay it there on the dresser so when I walk past it I will see it, and then I'll take it when it's early enough." Respondent \#1

\subsubsection{Fear of consequences}

For many of the participants, a great motivator to taking their anti-hypertensive medications was fear of the consequences of not taking them:

"Well I take the blood pressure pills because I don't want to fall out. I've been really scared because I don't like hospitals, and I didn't like how I was feeling when my head hurt like that. My friend died from an aneurysm, and she kept talking about headaches, and so fear makes me take them; but the other pills, I might skip them." Respondent \#10

\subsection{Use and comfort with technology based tools and tex- ting}

All 13 focus groups participants reported owning and using cell phones to call and receive text messages, as well as using the calendar for appointments. However, none reported using their phones for helping with medication-taking behavior.

"Yeah, I usually set and put my appointments in my phone, but I never thought to put 'Take your pills at such and such time.' I never thought to do that. But that's a good idea, like set a reminder in your phone "pill time, pill time."” Respondent \#2

While some of the participants were very comfortable with texting:

"I would rather text than talk. Especially on my phone 'cause I be like what? What you say? I can't hear you. Alright, I'm gonna text you.", Respondent \#7 
Others were less comfortable or preferred to talk instead of text:

"I don't care for it. I don't like texting. I'm not as fast as some people. I think my fingers are a little too big for them little numbers, buttons." Respondent \#6

"I text, it's okay. No problem but I'd rather talk, it's simpler than to do this and do that. Just say what I got to say. It's cool. I do know how to text and everything like that, but I'd rather talk." Respondent \#9

The general consensus among the participants, however, was that if they were to receive or send text messages, complete texts (message written out) not "textese" be used (e.g., ur instead of you are).

\subsection{Demonstration of the iTAB platform and partici- pant feedback}

Since the majority of effort in a texting intervention is in the initial programming of the automated system, it was important that feedback and suggestions for modifying the iTAB platform for the proposed $\mathrm{m}$-Health intervention be solicited from the focus group participants. Following a brief explanation about the proposed $\mathrm{m}$-Health intervention for helping with medication adherence, focus group participants were shown a slide presentation of the iTAB platform and asked to give their feedback, as well as suggestions for modifications. The presentation included examples of educational messages about BD and HTN, medication reminders, and a mood rating text message that patients would receive from iTAB. Participants were also given instructions on how to respond to the iTAB reminders and queries.

As illustrated in Table 4, overall response to the use of iTAB to help with medication adherence was very positive, and participants felt that iTAB had the potential to do more than be a medication reminder:

"Not only would it help you stay on your meds, but also stay healthy!” Respondent \#3

"It would let me know where I need some working on and if I'm inconsistent and what I need to do to get better. Then I can reach out and say okay you got some suggestions for me." Respondent \#8

Table 4. Feedback on iTAB demonstration by participants with HTN and BD $(n=13)$

\begin{tabular}{|c|c|}
\hline Themes and Categories & Illustrative Quotations from Respondents \\
\hline Positive Response to iTAB & $\begin{array}{l}\text { "Very good. What popped in my head was, why didn't I think of that? I would give it an A+!" } \\
\text { Respondent \#11 }\end{array}$ \\
\hline Text Message Preference & “I prefer complete texts. I don't like when people text in texties.” Respondent \#8 \\
\hline $\begin{array}{l}\text { Group Medications in Reminder } \\
\text { Texts }\end{array}$ & $\begin{array}{l}\text { "The text should say take your morning meds and in the evening, take your evening meds } \\
\text { because I take all my morning and then all my evening meds at the same time." Respondent \#10 }\end{array}$ \\
\hline Use Names of Medical Conditions & $\begin{array}{l}\text { "Name the condition. I don't really care 'cause it's not like I had AIDS or something. It's not } \\
\text { like I don't want nobody to know that I have bipolar and high blood pressure." Respondent \#9 }\end{array}$ \\
\hline $\begin{array}{l}\text { Provide Information on } \\
\text { Medication Risks and Benefits }\end{array}$ & $\begin{array}{l}\text { "It's very helpful to get information about the risks and benefits. You know they say knowledge } \\
\text { is power, so I think that's good to add it, so that way it would help." Respondent \#5 }\end{array}$ \\
\hline Agreeable to Rating Mood Daily & $\begin{array}{l}\text { “That would be great for me because due to my like short-term memory I don't have } \\
\text { remembrance of how many days I was feeling elevated or how many days I was feeling down. I } \\
\text { don't keep a journal. I don't write it down. Yeah, that's very helpful.” Respondent \#2 }\end{array}$ \\
\hline $\begin{array}{l}\text { Customize/Personalize Outgoing } \\
\text { Messages }\end{array}$ & $\begin{array}{l}\text { "I think you have to meet with each individual first and ask them about what times they take } \\
\text { their meds and what kind of message they'd like to receive." Respondent \#3 }\end{array}$ \\
\hline
\end{tabular}

Participants informed us they wanted to receive positive, rather than negative, messages about taking medication, and would be more likely to read and respond to these types of messages. Given that participants with BD and HTN were on multiple medications, they indicated a preference for receiving reminders about a group of medications taken at a particular time, or for a particular disorder, rather than specific medications. The majority of participants preferred that text messages name their medical condition directly, rather than use a code word, and also wanted to receive texts about both the benefits of taking medications as well as the risks of not taking them. Feedback about participant comfort with receiving a text message, and asking them to rate their mood on a scale once a day, was also positive, and their preference was for receiving and filling out the mood scale at the end of the day or evening:

"I would think evening after you've gone through most of the day to tell them." Respondent \#3 
The most salient feedback put forth by the participants was the need for customizing or personalizing the outgoing iTAB messages so that these messages would be optimal in improving medication-taking behavior.

\subsection{Modification and customization of the ITAB plat- form}

Results of the focus group findings were important in the modification and customization of the iTAB platform for the iTAB-CV intervention. Based on the feedback from the focus group participants as well as the technology team that developed the iTAB platform, the following decisions were made regarding iTAB-CV which would be tested for feasibility and acceptability in the subsequent Phase 2 of the study: 1) all feedback would be positive for reinforcement to messages, 2) feedback for answering questions about taking medications would also be positive; 3) participants could personalize the system by naming their condition; 4) participants could choose the window of time that messages would be received; and most importantly, 5) all individuals who would be enrolled in the Phase 2 study, would be interviewed as to their preferences for customization of their incoming and outgoing iTAB text messages.

Indeed, a major feature of the iTAB platform is that it can be customized with texts that are specific to the person, medication, and timing. Moreover, it can use the participant's own words for both reminders and reinforcers, and is flexible in being able to send reminders consistent with the participant's schedule. If medications are switched during the study, the iTAB platform can be updated. It will also be able to randomly select from a possible pool of reminders and reinforcers, assuring that texts do not become stale. The texts can also be customized to overcome existing barriers to adherence.

Preliminary acceptability results from the first seven subjects recruited for the iTAB-CV intervention in Phase 2, show that customization of the messages was well received and found to be useful. As far as increased knowledge, subjects felt they learned something about HTN and BD that they did not know before, and believed that the iTAB-CV texts addressed issues that were important to their particular situation. Subjects indicated that they would like to continue the use of iTAB-CV after the study, if given the choice, and were enthusiastic about recommending the program to others.

\section{Discussion}

As patient engagement can lead to better outcomes, ${ }^{[33,34]}$ care approaches that enhance the involvement of patients in monitoring and targeting their own health behaviors have the potential to improve adherence in people with mental illness and medical comorbidity. The present study used an iterative, collaborative process to inform the development of an m-Health intervention for patients with both BD and HTN. To the best of our knowledge, this is the first study to develop and test an $\mathrm{m}$-Health intervention in this sub-group of individuals with both these chronic illnesses. The study identified barriers and facilitators to adherence in patients with both these chronic illnesses, and provided input on how an $m$-Health intervention might be used. Several observations deserve mention. Forgetfulness was the most frequently mentioned barrier to taking antihypertensive medications, and decisions about taking them were often influenced by BD mood fluctuations. Prospective memory, the ability to remember to carry out a given task at some point in the future, can be impaired in BD. Executive functioning deficits, including problems with planning or organizational abilities, may disrupt medication taking even when an individual intends to take medication. ${ }^{[35]}$ The burden of having "too many pills" ultimately influenced decisions about the number and types of medications an individual would take. For individuals living with multiple comorbidities, the onerous task of managing multiple medications is well documented. ${ }^{[36,37]}$ Other key barriers to adherence with drugs for HTN included side effects, and competing demands of life activities that diverted attention from health management.

With respect to adherence facilitators, while many participants used pill boxes, calendars, and routines to remind them to take both HTN and BD medications, reminder phone calls from family and friends appeared to be the most important facilitator to medication adherence for both chronic illnesses. Even though these phone reminders might not guarantee adherence, they may serve as a form of social support, known to be helpful in chronic disease management. ${ }^{[22,38,39]}$ Additionally, the negative consequences of not taking medication, especially for blood pressure control, was a clear motivator to remain adherent. Finally, several participants noted that at times they are adherent to BD medication and not HTN, or vice versa, which is consistent with the literature ${ }^{[40,41]}$ and suggests that texts to support adherence alone may not be sufficient to change behavior.

With respect to developing an m-Health approach to promote adherence, while participants with BD and HTN were very comfortable using their phones, none were using phonebased technology to improve adherence. Despite not using mobile technology for this purpose, participants were very open to $\mathrm{m}$-Health in principle, and noted that it might address barriers and enhance facilitators to adherence. To address the issue of forgetting, participants endorsed the use of text message reminders, and were consistent with a preference for simplicity. They wanted to receive reminders about a 
group of medications taken at a particular time, or for a particular disorder, rather than specific medications. The majority of participants preferred that text messages name their medical condition directly, rather than use a code word, and also wanted to receive texts about both the benefits of taking medications as well as the risks of not taking them.

Emphasizing the relatively greater impact of support versus criticism in addressing poor adherence, participants preferred positive, rather than negative feedback, regarding their medication-taking behavior. It is possible that $\mathrm{m}$-Health communications could augment the positive support and reminders that they already receive from family members. Perhaps the most salient feedback in operationalizing the $\mathrm{m}$-Health intervention was the need to customize or personalize the outgoing iTAB messages for each individual on the receiving end. Examples of personalizing outgoing text messages could include using the individual's own words to describe their health conditions, sending text messages at times that they are most likely to receive and read them, allowing them the opportunity to opt out of receiving messages with predetermined content, and adding messages and reinforcers with personalized content. Personalizing reminders and reinforcers is an advantage over previous studies that have focused on medication timing and dosing, but did not tailor the reminder itself. ${ }^{[42]}$ This suggests that it is preferable to invest some initial time and effort in matching and meeting end-user needs prior to $\mathrm{m}$-Health roll-out vs. use of "off-the-shelf" apps or m-Health approaches. A recent qualitative review of mobile apps for general health conditions identified key themes that need to be considered in developing conditions-specific approaches including addressing: 1) barriers to adoption of health apps, 2) barriers to continued use of health apps, 3) motivators, 4) information and personalized guidance, 5) tracking for awareness and progress, 6) credibility, 7) goal setting, 8) reminders, and 9) sharing personal information. ${ }^{[43]}$ Importantly, a recent systematic literature review focused on mobile apps specific to BD noted that the content of currently available apps for $\mathrm{BD}$ are not in line with practice guidelines or established selfmanagement principles. ${ }^{[44]}$ As the authors of the literature review point out, the opportunity for $\mathrm{m}$-Health to assist in the self-management of BD is a field that is still in its infancy.

Whereas our findings have implications for informing care delivery for patients with BD and HTN, there are some limitations. We acknowledge the sample demographics appear biased with regard to gender, age, and ethnicity, but are consistent with the demographics of the recruitment area, ${ }^{[25]}$ as described in the Sample and Setting section. The small purposive sample of mainly middle aged African-American women, and the conduct of the study in a single urban area, may limit the transferability of the study findings. Patients with BD and HTN who are male, of a younger age, consist of other racial backgrounds, and are from other parts of the country, may have different experiences with medication adherence and alternative suggestions about the development of the m-Health intervention. Nevertheless, these limitations are offset, to some extent, by the use of rigorous qualitative methods, which are consistent with guidelines outlines in the Consolidated Criteria for Reporting Qualitative research $(\mathrm{COREQ})^{[45]}$ to improve the rigor, comprehensiveness and credibility of focus groups. These self-report methods are direct, versatile, and yield information that would be difficult, if not impossible, to gather by other means. Additionally, the strong representation of African American participants in the focus groups may be considered a strength given that African Americans are often underrepresented in health research. ${ }^{[46]}$

\section{Conclusions}

Barriers to medication adherence in people living with BD and HTN are numerous and cross multiple levels, including factors related to bipolar pathology and those unique to an individual's circumstances. Personal mobile phones are widely used by individuals with BD and HTN, and when used as part of an m-Health intervention, they have the potential to improve adherence with both BD and HTN medications in individuals with known sub-optimal adherence. Adherence enhancement approaches need to specifically target forgetting or cognitive barriers to adherence, augment existing psychosocial supports, reinforce healthy behaviors, and be customized to the unique needs and preferences of this sub-group of individuals with $\mathrm{BD}$ and comorbid chronic health conditions such as HTN. mHealth approaches that focus on vulnerable sub-groups with BD may improve health outcomes in populations that would otherwise have a poor prognosis.

\section{ACKNOWLEDGEMENTS}

This study was supported by a grant from the National Heart Lung and Blood Institute (NHLBI) 1R21HL132364-01 (PI Levin) and by the Clinical and Translational Science Award (CTSC) - UL1TR 00043for REDCap.

\section{CONFlicts of InTEREST Disclosure}

Dr. Sajatovic has research grants from Alkermes, Pfizer, Merck, Janssen, Reuter Foundation, Woodruff Foundation, Reinberger Foundation, National Institute of Health (NIH), and the Centers for Disease Control and Prevention (CDC). Dr. Sajatovic is a consultant to Bracket, Otsuka, Supernus, Neurocrine, Health Analytics and Sunovion and has received royalties from Springer Press, Johns Hopkins University Press, Oxford Press, and UpToDate. Dr. Moore has research 
grants from National Institute of Health (NIH), California HIV/AIDS Research Program, and Gilead Sciences has provided study drug for work unrelated to this project.
Dr. Blixen, Dr. Depp, Mr. Cushman, Dr. Cage, Ms. Barboza, Mr. Eskew, Ms. Cassidy, and Dr. Levin declare no conflicts of interest.

\section{REFERENCES}

[1] Siantz E, Aranda MP. Chronic disease self-management interventions for adults with serious mental illness: a systematic review of the literature. Gen Hosp Psychiatry. 2014; 36(3): 233-44. PMid:24630896. https://doi.org/10.1016/j.genhosppsych.2014.01.014

[2] Colton CW, Manderscheid RW. Congruencies in increased mortality rates, years of potential life lost, and causes of death among public mental health clients in eight states. Prev Chronic Dis. 2006; 3(2): A42. PMid:16539783.

[3] Birkenaes AB, Opjordsmoen S, Brunborg C, et al. The level of cardiovascular risk factors in bipolar disorder equals that of schizophrenia: a comparative study. J Clin Psychiatry. 2007; 68(6): 917-23. PMid:17592917. https://doi .org/10.4088/JCP.v68n0614

[4] Ramsey CM, Leoutsakos JM, Mayer LS, et al. History of manic and hypomanic episodes and risk of incident cardiovascular disease: 11.5 year follow-up from the Baltimore Epidemiologic Catchment Area Study. J Affect Disord. 2010; 125(1-3): 35-41. PMid:20570367. https://doi.org/10.1016/j.jad.2009.12.024

[5] Ramsey CM, Spira AP, Mojtabai R, et al. Lifetime manic spectrum episodes and all-cause mortality: 26-year follow-up of the NIMH Epidemiologic Catchment Area Study. J Affect Disord. 2013; 151(1): 337-42. PMid:23835104. https ://doi .org/10.1016/j.jad. 20 13.06 .019

[6] Weiner M, Warren L, Fiedorowicz JG. Cardiovascular morbidity and mortality in bipolar disorder. Ann Clin Psychiatry. 2011; 23(1): 40-7 PMid:21318195.

[7] Westman J, Hallgren J, Wahlbeck K, et al. Cardiovascular mortality in bipolar disorder: a population-based cohort study in Sweden. BMJ Open. 2013; 3(4). PMid:23604348. https : //doi.org/10.1136/ bmjopen-2012-002373

[8] Goldstein BI, Schaffer A, Wang S, et al. Excessive and premature new-onset cardiovascular disease among adults with bipolar disorder in the US NESARC cohort. J Clin Psychiatry. 2015; 76(2): 163-9. PMid:25742203. https : //doi.org/10.4088/JCP. 14m09300

[9] Goldstein BI, Fagiolini A, Houck P, et al. Cardiovascular disease and hypertension among adults with bipolar I disorder in the United States. Bipolar Disord. 2009; 11(6): 657-62. PMid:19689508. https://doi.org/10.1111/j.1399-5618.2009.00735.x

[10] Costa FV. Compliance with antihypertensive treatment. Clin Exp Hypertens. 1996; 18(3-4): 463-72. PMid:8743035. https://doi. org/10.3109/10641969609088977

[11] Cramer JA, Benedict A, Muszbek N, et al. The significance of compliance and persistence in the treatment of diabetes, hypertension and dyslipidaemia: a review. Int J Clin Pract. 2008; 62(1): 76-87. PMid:17983433. https://doi.org/10.1111/j.1742-1241.20 $07.01630 . \mathrm{x}$

[12] Viswanathan M, Golin CE, Jones CD, et al. Closing the quality gap: revisiting the state of the science (vol. 4: medication adherence interventions: comparative effectiveness). Evid Rep Technol Assess (Full Rep). 2012(208.4): 1-685.

[13] Nieuwlaat R, Wilczynski N, Navarro T, et al. Interventions for enhancing medication adherence. Cochrane Database Syst Rev. 2014; 11: CD000011. https://doi.org/10.1002/14651858.CD000 $011 \cdot$ pub4
[14] Levin JB, Krivenko A, Howland M, et al. Medication Adherence in Patients with Bipolar Disorder: A Comprehensive Review. CNS Drugs. 2016; 30(9): 819-35. PMid:27435356. https ://doi.org/ $10.1007 / \mathrm{s} 40263-016-0368-\mathrm{x}$

[15] Cole-Lewis H, Kershaw T. Text messaging as a tool for behavior change in disease prevention and management. Epidemiol Rev. 2010; 32(1): 56-69. PMid:20354039. https://doi.org/10.1093/ep irev/mxq004

[16] Berrouiguet S, Baca-García E, Brandt S, et al. Fundamentals for Future Mobile-Health (mHealth): A Systematic Review of Mobile Phone and Web-Based Text Messaging in Mental Health. J Med Internet Res. 2016; 18(6): e135. PMid:27287668. https: //doi.org/10.2196/jmir.5066

[17] Depp CA, Mausbach B, Granholm E, et al. Mobile interventions for severe mental illness: design and preliminary data from three approaches. J Nerv Ment Dis. 2010; 198(10): 715-21. PMid:20921861. https ://doi.org/10.1097/NMD.0b013e3181f49ea3

[18] Depp CA, Moore RC, Perivoliotis D, et al. Technology to assess and support self-management in serious mental illness. Dialogues Clin Neurosci. 2016; 18(2): 171-83. PMid:27489457.

[19] Moore DJ, Poquette A, Casaletto KB, et al. Individualized Texting for Adherence Building (iTAB): Improving Antiretroviral Dose Timing Among HIV-Infected Persons with Co-occurring Bipolar Disorder. AIDS Behav. 2014; 19(3): 459-71. PMid:25504449. https : //doi.org/10.1007/s10461-014-0971-0

[20] Moore DJ, Montoya JL, Blackstone K, et al. Preliminary Evidence for Feasibility, Use, and Acceptability of Individualized Texting for Adherence Building for Antiretroviral Adherence and Substance Use Assessment among HIV-Infected Methamphetamine Users. AIDS Res Treat. 2013; 2013: 585143. https ://doi.org/10.1155/20 $13 / 585143$

[21] Mehregany M, Saldivar E. Opportunities and Obstacles in the Adoption of mHealth. In: Korohn R, Metcalf D, editors. mHealth From smartphones to smart systems. Chicago, IL: Healthcare Information and Management Systems Society (HIMSS); 2012. 7-24 p.

[22] Montoya JL, Georges S, Poquette A, et al. Refining a personalized mHealth intervention to promote medication adherence among HIV+ methamphetamine users. AIDS Care. 2014; 26(12): 1477-81. PMid:24911433. https ://doi.org/10.1080/09540121. 2014. 924213

[23] Grypdonck MH. Qualitative health research in the era of evidencebased practice. Qual Health Res. 2006; 16(10): 1371-85. PMid:17079799. https ://doi .org/10.1177/10497323062940 89

[24] Krueger RA. Focus Groups: A Practical Guide for Applied Research. Thousand Oaks, California: Sage; 1994.

[25] Bureau USC. American Community Survey 5-year estimates. Retrieved from Census Reporter Profile page for East Cleveland, $\mathrm{OH}$ 2015. Available from: https://censusreporter.org/profile s/16000US3923380-east-cleveland-oh/

[26] Strauss A. A qualitative analysis for social scientists. New York, NY: Cambridge University Press; 1988.

[27] Creswell JW. Qualitative Inquiry \& Research Design: Choosing Among Five Approaches. Thousand Oaks, CA: Sage; 2007. 
[28] Denzin NK, Lincoln YS. The Discipline and Practice of Qualitative Research. The Sage Handbook for Qualitative Research. 3rd ed. Thousand Oaks, CA: Sage; 2005. 1-32 p.

[29] Morse J. Qualitative Health Research. Thousand Oaks, CA: Sage; 2002.

[30] Bradley EH, Curry LA, Devers KJ. Qualitative data analysis for health services research: developing taxonomy, themes, and theory. Health Serv Res. 2007; 42(4): 1758-72. PMid:17286625. https: //doi.org/10.1111/j.1475-6773.2006.00684.x

[31] Patton M. Enhancing the quality and credibility of qualitative analysis. Health Services Research. 1999; 34(5): 1189-208. PMid:10591279.

[32] Cresswell J, Miller D. Determining validity in qualitative inquiry. Theor Pract. 2000; 39(3): 4-7. https ://doi.org/10.1207/s154 30421tip3903_2

[33] Carmen K, Dardess P, Maurer M, et al. Patient and Family Engagement: A Framework for Understanding the Elements and Developing Interventions and Policies. Health Affairs. 2013; 32(2): 223-31. PMid:23381514. https://doi.org/10.1377/hlthaff . 2012.1 133

[34] Pelletier JF, Rowe M, François N, et al. No personalization without participation: on the active contribution of psychiatric patients to the development of a mobile application for mental health. BMC Med Inform Decis Mak. 2013; 13: 78. PMid:23890085. https: //doi.org/10.1186/1472-6947-13-78

[35] Lee E, Xiang YT, Man D, et al. Prospective Memory Deficits in Patients with Bipolar Disorder: a Preliminary Study. Arch Clin Neuropsychol. 2010; 25(7): 640-7. PMid:20716545. https ://doi .or $\mathrm{g} / 10.1093 /$ arclin/acq061

[36] Mishra SI, Gioia D, Childress S, et al. Adherence to medication regimens among low-income patients with multiple comorbid chronic conditions. Health Soc Work. 2011; 36(4): 249-58. PMid:22308877. https://doi.org/10.1093/hsw/36.4.249

[37] Cantudo-Cuenca MR, Jiménez-Galán R, Almeida-Gonzalez CV, et al. Concurrent use of comedications reduces adherence to antiretroviral therapy among HIV-infected patients. J Manag Care Spec Pharm. 2014; 20(8): 844-50. https://doi.org/10.18553/jmcp. 2014 .20 .8 .844
[38] Gallant MP. The influence of social support on chronic illness selfmanagement: a review and directions for research. Health Educ Behav. 2003; 30(2): 170-95. PMid:12693522. https://doi.org/ 10.1177/1090198102251030

[39] Garofalo R, Kuhns LM, Hotton A, et al. A Randomized Controlled Trial of Personalized Text Message Reminders to Promote Medication Adherence Among HIV-Positive Adolescents and Young Adults. AIDS Behav. 2016; 20(5): 1049-59. PMid:26362167. https : //doi.org/10.1007/s10461-015-1192-x

[40] Levin JB, Aebi ME, Tatsuoka C, et al. Adherence to Psychotropic and Nonpsychotropic Medication Among Patients With Bipolar Disorder and General Medical Conditions. Psychiatr Serv. 2016; 67(3): 342-5. PMid:26695494. https://doi.org/10.1176/appi.ps. 201500 010

[41] Levin JB, Krivenko A, Bukach A, et al. A Reexamination of Nonpsychiatric Medication Adherence in Individuals With Bipolar Disorder and Medical Comorbidities. J Nerv Ment Dis. 2016.

[42] Andrade AS, McGruder HF, Wu AW, et al. A programmable prompting device improves adherence to highly active antiretroviral therapy in HIV-infected subjects with memory impairment. Clin Infect Dis. 2005; 41(6): 875-82. PMid:16107989. https://doi .org/10.108 $6 / 432877$

[43] Peng W, Kanthawala S, Yuan S, et al. A qualitative study of user perceptions of mobile health apps. BMC Public Health. 2016; 16(1): 1158. PMid:27842533. https://doi.org/10.1186/s12889-0 16-3808-0

[44] Nicholas J, Larsen ME, Proudfoot J, et al. Mobile Apps for Bipolar Disorder: A Systematic Review of Features and Content Quality. J Med Internet Res. 2015; 17(8): e198. PMid:26283290. https : //doi.org/10.2196/jmir.4581

[45] Tong A, Sainsbury P, Craig J. Consolidated criteria for reporting qualitative research (COREQ): a 32-item checklist for interviews and focus groups. Int J Qual Health Care. 2007; 19(6): 349-57. PMid:17872937. https://doi.org/10.1093/intqhc/mzm042

[46] George S, Duran N, Norris K. A systematic review of barriers and facilitators to minority research participation among African Americans, Latinos, Asian Americans, and Pacific Islanders. Am J Public Health. 2014; 104(2): e16-31. PMid:24328648. https: //doi.org/10.2105/AJPH.2013.301706 